\title{
Genomic coalescence in a population of Laxmannia sessiliflora (Angiospermae, Anthericaceae): an association of lethal polymorphism, self-pollination and chromosome number reduction
}

\author{
SIDNEY H. JAMES $†$, GREG K. KEIGHERY $\$$, ADRIAN MOORREES§ \\ \& MICHELLE WAYCOTT* ${ }^{*} \dagger$ \\ Department of Botany, The University of Western Australia, Nedlands, Western Australia 6907, Australia
}

\begin{abstract}
A population of Laxmannia R. Br. (Angiospermae, Anthericaceae) near Collie, Western Australia, combines the taxonomically significant sessile inflorescences of $L$. sessiliflora Dcne. $(n=4)$ and the derived breeding system of $L$. ramosa Lindl. $(n=4)$. It exhibits a polymorphism for seed-aborting lethal equivalents, significant levels of self-pollination and a chromosome polymorphism in which a haploid genome with $n=3$ is most frequent. Allozyme analysis indicates that the population is either of hybrid origin or one that has uniquely diverged from a phylogenetic link between the two species. The population is considered to represent a natural demonstration of the phenomenon of genomic coalescence as modelled by James (1992, Heredity, 68, 449-456) in which devices which reduce the number of independently segregating supergenes heterozygous for recessive lethals are elevated to high frequencies by inbreeding. The population also suggests a mechanism whereby dysploid chromosome number reduction may be promoted by natural selection in natural population systems.
\end{abstract}

Keywords: chromosome polymorphism, dysploidy, genomic coalescence, Laxmannia, lethal polymorphism, self-pollination.

\section{Introduction}

Chromosome repatterning is a characteristic feature of the speciation process (Stebbins, 1950; Dobzhansky, 1951; Grant, 1971; White, 1978) and speciation without chromosome repatterning, as in the homosequential species complexes of Hawaiian Drosophilids (Carson et al., 1970) is uncommon (White, 1978). However, the evolutionary processes by which chromosome rearrangements, especially those resulting in chromosome number changes, may become fixed in populations are complex and not well documented. All structural mutations, including those which are necessary to rearrange the genome onto a different number of

*Correspondence. E-mail: michelle.waycott@jcu.edu.au

$\dagger$ Deceased 7/12/1998.

$\$$ Present address: Department of Conservation and Land Management, Woodvale, Western Australia, 6026, Australia.

§Present address: Department of Natural Resources and Environment, East Melbourne, Victoria, Australia.

$\dagger \dagger$ Present address: Smithsonian Tropical Research Institute, Balboa, Republic of Panama. centromeres, must initially occur at very low frequencies in the population, and as heterozygotes. These structural heterozygotes must be of reduced fitness because of the meiotic irregularity they cause and, other things being equal, they should be removed from the population by natural selection.

Following an analysis of the evolution of complex hybridity in Isotoma petraea (James, 1965; James et al., 1990, 1991), James (1992) demonstrated that interchange heterozygosity, or other devices that link supergenes that are heterozygous for recessive lethal equivalents, would be elevated to high frequencies under conditions of inbreeding. He referred to this phenomenon as 'genomic coalescence' and suggested that it is the basis of a common evolutionary pathway which has lead to dysploid chromosome number reduction in several Australian plant groups and to other systems which tie otherwise independently segregating chromosomal units together (James, 1996).

In this paper, the breeding systems of Laxmannia sessiliflora and L. ramosa are described and a chromosomally variable population of $L$. sessiliflora from near 
Collie, Western Australia is compared with more regular populations of the two species. This population appears to exhibit genomic coalescence en flagrante.

\section{Materials and methods}

\section{The species and their genetic systems}

Laxmannia sessiliflora Dcne. and Laxmannia ramosa Lindl. are two stilt-rooted species of the Anthericaceae, a family recently separated from the Liliaceae (Dahlgren et al., 1985). The species commonly occur in a variety of habitats throughout the south-west of Western Australia, and are small inconspicuous herbs growing to a height of $10-20 \mathrm{~cm}$. Both species grow in the sandy spaces between larger shrubs of the kongwan and banksia woodlands and on the lateritic gravel of the jarrah forest, sometimes in mixed populations.

Laxmannia sessiliflora is readily distinguished from L. ramosa (Keighery, 1987). In the former, the inflorescences are sessile within leaf axils, or rarely with short decurved peduncles, and the sepals are white whereas in L. ramosa, the inflorescences are borne on straight peduncles exceeding the leaves, and the sepals are lined red. The species are especially different, however, in terms of their genetic systems (Keighery, 1987) (Table 1). Laxmannia sessiliflora has a single ovule in each of its three locules (three ovules per flower) whereas L. ramosa has two ovules per locule (six ovules). Both species have a chromosome number of $2 n=8$. In addition, we observed that, in L. ramosa, the anthers in recently closed buds are adpressed against the stigma so that self-pollination is regularly achieved on flower closure. There was no evidence for self-pollination on flower closure in L. sessiliflora.

In addition to L. sessiliflora and L. ramosa having the characteristics outlined above, three aberrant populations of related Laxmannia have been observed at Stirling Ranges, Porongurups and Collie. Because they have sessile inflorescences, the populations are considered to be taxonomically closer to L. sessiliflora than L. ramosa, and they have been grouped as L. sessiliflora* in Table 1 . However, these forms have a more straggling L. ramosalike habit and their sepals are lined red. They also have two ovules per locule and they self-pollinate on flower closure. Chromosome numbers of $2 n=8$ have been recorded in the Stirling Ranges population, whereas $2 n=7$ and 6 were found in the Collie population. The Collie population is the population of particular interest in this paper.

\section{Seed- and fruit-set analysis}

Plants were potted in the field and transported to a relatively insect-free glasshouse at The University of
Western Australia. Anthers containing pollen were dabbed onto the stigma of the same flower to effect self-pollination. Open flowers were emasculated with fine forceps and pollinated using whole anthers from a different plant to effect cross-pollination. The perianths of pollinated flowers, which persist until the fruits mature, were colour-coded with inks to allow subsequent identification. The number of pollinated flowers which set fruit was recorded. At maturity and before dehiscence, the numbers of fully formed and partly developed seeds were recorded for each fruit by dissection and counting.

A series of pollination experiments was also conducted in the field so that fruit-set in the field and seed-set within retained fruits could be assessed. Some plants with marked but otherwise untreated flowers were covered with fine muslin cages to impede insect visits.

\section{Karyotype analysis}

Root tips, preferably newly formed and actively growing stilt roots that had not yet reached the soil surface, were harvested, pretreated with $0.1 \%$ colchicine for $3 \mathrm{~h}$ and fixed in 3 absolute alcohol:1 glacial acetic acid for at least $1 \mathrm{~h}$ but not longer than $24 \mathrm{~h}$, hydrolysed, stained and squashed according to the Feulgen technique. Good metaphase spreads were photographed and karyotypes assembled in the usual fashion.

Karyotypes in normal L. sessiliflora and L. ramosa were constant and all plants appeared homokaryotypic for an $n=4$ genome consisting of three large acrocentrics, which were all separately recognizable on the basis of overall size and centromere position, and a smaller subtelocentric (karyotype 1, Fig. 1). This genome is very similar to that characterizing other Laxmannia species and also the related Sowerbaea juncea (Stewart \& Barlow, 1976), and was designated the A genome. Variant karyotypes among 47 plants from the Collie $L$. sessiliflora* population were sorted into their component haploid genomes on the basis of minimal departures from the standard A genome. The analysis was limited to gross differences that could be confidently recognized by inspection only.

\section{Isoenzyme variation}

Fresh leaf and shoot-tip material was collected from four populations, namely

CS*: L. sessiliflora*, from a wet shrubland depression, $15 \mathrm{~km}$ ESE of Collie on the S side of Coalfields Rd.

CR: L. ramosa, from a low grey sand hillside, $12 \mathrm{~km}$ ESE of Collie on the $\mathrm{S}$ side of Coalfields Rd.

PS: L. sessiliflora, from a clayey grey sand colluvial flat in the Swan Shire Recreation Reserve, Stratton (a Perth suburb). 
Table 1 Genetic systems of Laxmannia taxa

\begin{tabular}{|c|c|c|c|c|}
\hline \multicolumn{2}{|l|}{ Genetic system component } & L. sessiliflora & L. sessiliflora* & L. ramosa \\
\hline $2 n$ & & 8 & $6,7,8$ & 8 \\
\hline Pollination & & Open & Selfing on closure & Selfing on closure \\
\hline $\begin{array}{l}\text { Fruit set } \\
P \text { (flower } \rightarrow \text { fruit) }\end{array}$ & $\begin{array}{l}\text { On selfing } \\
\text { On crossing } \\
\text { In field } \\
\text { In field, caged }\end{array}$ & $\begin{array}{l}0.912(283,10,4)^{1} \\
0.898(147,7,2) \\
0.482(1385,10,2) \\
0.372(556,5,1)^{4}\end{array}$ & $\begin{array}{l}0.515^{2}(136,7,2) \\
0.391^{3}(115,6,2)\end{array}$ & $\begin{array}{l}0.171(677,19,3) \\
0.893(112,5,2) \\
0.364(762,5,1)\end{array}$ \\
\hline $\begin{array}{l}\text { Seed set } \\
P(\text { ovule } \rightarrow \text { seed }) \text { in fruit }\end{array}$ & $\begin{array}{l}\text { In field } \\
\text { In glasshouse }\end{array}$ & $0.950(963,6,1)^{5}$ & $\begin{array}{l}0.490\left(176,10,1^{6}\right) \\
0.494\left(114,10,1^{7}\right)\end{array}$ & $0.513(277,5,1)$ \\
\hline
\end{tabular}

${ }^{1} P$ (flowers, plants, populations). ${ }^{2} 0.854$ in pop. $1,0.000$ in pop. $2 .{ }^{3} 0.7333$ in pop. $1,0.018$ in pop. $2 .{ }^{4}$ In this population the fruit-set in uncaged plants was 0.557 (422 flowers, 4 plants). ${ }^{5} P$ (fruits, plants, populations). ${ }^{6}$ Pop. $2 .{ }^{7}$ Pop. $1 .{ }^{8} P$ (flowers, plants, populations).

PR: L. ramosa, from a clayey grey sand colluvial flat in the Swan Shire Recreation Reserve, Stratton (a Perth suburb). (PS and PR grow together in a mixed population.)

The material was stored in sealed plastic bags on ice while being transported to the laboratory, where individual samples were placed in tubes and frozen at $-80^{\circ} \mathrm{C}$ until grinding immediately prior to allozyme analysis. Approximately $25 \mathrm{mg}$ of tissue was homogenized in $20 \mu \mathrm{L}$ of phosphate grinding buffer (Sampson et al., 1994), wicks of chromatography paper were added and loaded onto $11.25 \%$ starch gels, which were run as described by Wendel \& Weeden (1989) using the buffers and methods described by Waycott et al. (1997).

Good quality electrophoretograms were obtained for five enzyme systems (IDH, EC 1.1.1.42; GPI, EC 5.3.1.9; MDH, EC 1.1.1.37; PGM, EC 5.4.2.2; PGD, EC 1.1.1.44) yielding six readily interpretable loci. No Mendelian analysis of electrophenotypes was undertaken.

\section{Results}

\section{Seed- and fruit-set analysis}

The two species, L. sessiliflora and L. ramosa, differ in their fruit- and seed-set responses (Table 1). In $L$. sessiliflora, about $90 \%$ of the flowers that were selfpollinated or cross-pollinated on plants transferred to the glasshouse set fruit. However, only about $50 \%$ of flowers set fruit in the field, and this yield was reduced to $37 \%$ on plants that were caged so as to impede flying insect vectors. Small crawling insects may well be important in pollinating $L$. sessiliflora, and these may effect more self-pollination than cross-pollination. About $95 \%$ of the ovules in field-collected fruit of $L$. sessiliflora had developed into seed. We conclude that there is no impediment to seed formation, apart from a requirement for vector-mediated pollination, in $L$. sessiliflora.

In $L$. ramosa, fruit- and seed-set is reduced by impedimenta other than pollination limitations. Although essentially all the flowers will be pollinated because they are automatically self-pollinated on flower closure, they are open during the day and may first be visited by cross-pollinating vectors. However, in the field, only $36.4 \%$ of 762 marked flowers set fruit (Table 1). Artificial self-pollinations resulted in a $17.1 \%$ fruit-set whereas artificial crosses resulted in $89.3 \%$ fruit-set, and results for glasshouse- and fieldconducted hand-pollination experiments were comparable. If, in the field, the probability of cross-pollination is $x$, then using the data recorded in Table 1, we might propose:

$0.893 x+0.171(1 \quad x)=0.364$

whence $x=0.267$, suggesting that $27 \%$ of all pollination events are outcrosses, whereas $73 \%$ are selfs.

The probability that an ovule in a self-pollinated flower in L. ramosa became a fully developed seed was only 0.053 , whereas $P$ (ovule $\rightarrow$ seed) following crossing was 0.574 , and under field pollination conditions was 0.187 (Table 1). These data again allow a confirmation of the field pollination regime to be about $1 / 4$ crossing and $3 / 4$ selfing. Partly developed seeds were common in 
KARYOTYPE

\section{1}

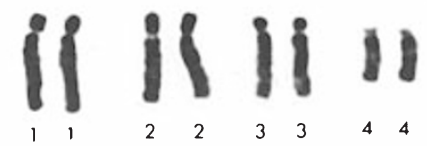

2 iा il
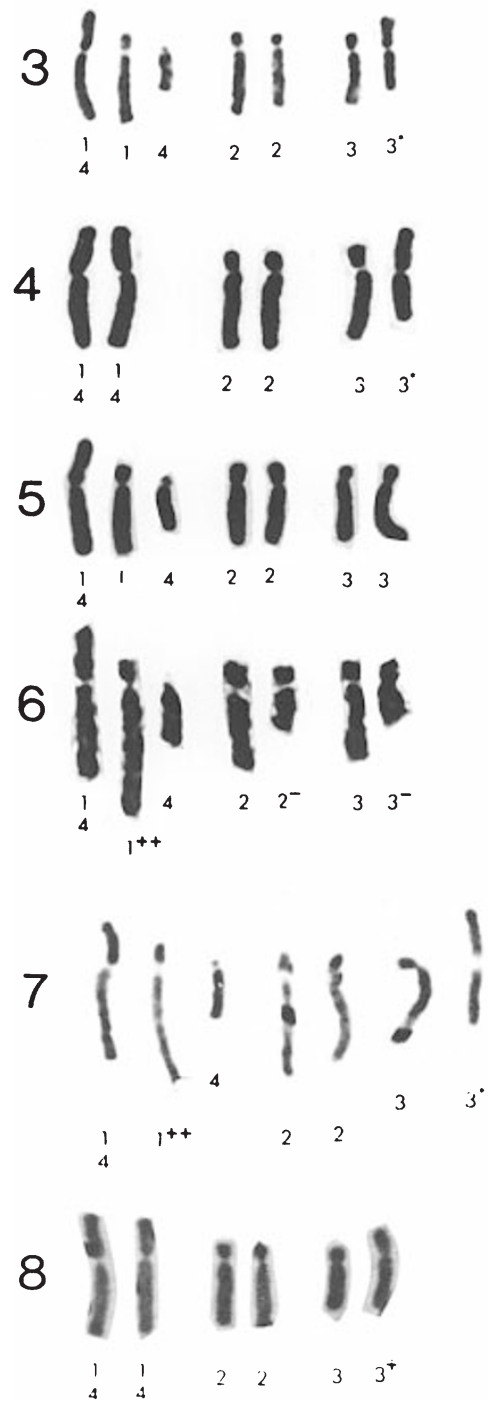

NEW GENOME

A

B

B B

$\begin{array}{lll}1 & 2 & 3\end{array}$

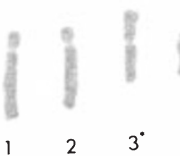

C

B C

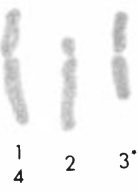

D

B D

A B

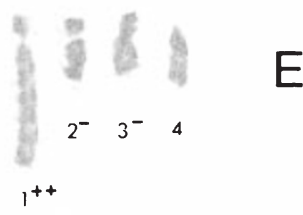

$\mathrm{F}$

B F

G

B G

Fig. 1 Karyotypes in Laxmannia sessiliflora from Perth (karyotype 1) and from L. sessiliflora* (CS*) (karyotypes 2-8). The normal 4 , the small subtelocentric in genomes $\mathrm{A}, \mathrm{C}, \mathrm{E}$ and $\mathrm{F}$, is from $4 \mu \mathrm{m}$ to $5 \mu \mathrm{m}$ in length.

all fruit types and accounted for about $25 \%$ of the units showing postzygotic development in the selfed fruits. The inbreeding depression $(\partial)$ for fruit and seed-set exhibited by L. ramosa $\left(\partial_{\text {fruit }}=1-0.171 / 0.893=\right.$ $\left.0.809, \partial_{\text {seed }}=1-0.053 / 0.574=0.908\right)$, and the obvious seed abortion, must be attributed to homozygosity

(C) The Genetical Society of Great Britain, Heredity, 82, 364-372. 
for seed-aborting recessive lethal equivalents. That is, L. ramosa populations are characteristically polymorphic for seed-aborting recessive lethals (or lethal equivalents).

The L. sessiliflora* populations appear to be polymorphic for seed-aborting lethal polymorphisms but the data reported here are somewhat confusing. With respect to the fruit-set data obtained in the glasshouse, it appears that Population 1 (Stirling Ranges) may be devoid of a lethal polymorphism, whereas Population 2 (Porongurups) may carry an abundance of lethals, many of them shared by neighbouring plants within the population, so that fruit-set is very low following either self- or cross-pollination. On the other hand, the Population 2 plants may have been damaged on transfer from the field. The seed-sets within fruits of Population 1 plants in the glasshouse and of Population 2 plants in the field were comparable at about $49 \%$, indicating that considerable levels of seed abortion characterize both populations. The lethal polymorphism was not quantified in the third population, Collie, but was obvious because of the low seed-set and the occurrence of a high frequency of aborted products in field-collected fruit.

\section{Karyotype variation in the Collie L. sessiliflora* population}

The standard karyotype from Perth material of normal L. sessiliflora and seven aberrant karyotypes identified amongst 47 Collie L. sessiliflora* (CS*) plants are illustrated in Fig. 1. Karyotype 1 is from the Perth material. It consists of four pairs of chromosomes numbered 1, 2, 3 and 4, and is homokaryotypic (homozygous) for the A genome. Karyotype 2 (CS*) is homozygous for a three-chromosomed B genome, which may be derived from the A genome by fusion of chromosomes 1 and 4 , to yield the distinctive ${ }_{4}^{1}$ large submetacentric. A combination of genomes A and B yields karyotype 5. Karyotype 3 has seven chromosomes, three of which are recognizable as genome B. The remaining four constitute a new genome $\mathrm{C}$ which may be derived from genome A by pericentric inversion of chromosome 3 to yield the smaller metacentric denoted $3^{*}$. Recombination in a BC heterogenome could produce genome D containing chromosomes ${ }_{4}^{1}, 2$ and $3^{*}$; genome D exists along with genome B in karyotype 4 . Karyotype 6 comprises seven chromosomes from which genome B can be extracted. The remaining four chromosomes include one acrocentric with an extended long arm, and two shortened acrocentrics. These chromosomes, denoted $1^{++}, 2^{-}$and $3^{-}$, along with a normal 4 , constitute the new genome E. Similarly, karyotype 7 comprises genome $\mathrm{B}$ and a new genome $\mathrm{F}$ which includes the $1^{++}$and the $3^{*}$ chromosomes along with normal chromosomes 2 and 4 . Karyotype 8 is similar to the $\mathrm{BB}$ homogenome (karyotype 2), except that its chromosome $3^{+}$has a short arm larger than the normal 3 and shorter than that of $3^{*}$, thus defining genome G. A total of seven different haploid genomes was recognized, either $n=4$ (A, similar to the standard genome, C, E and $\mathrm{F}$ ) or $n=3$ (B, D and G). Statistical analysis of chromosome arm measurements confirmed that the two most similar genomes (D and G) contained distinctly different chromosomes (data not shown).

BB $(2 n=6)$ was the only homokaryotype observed in the Collie population, and only those chromosomes contained within the B genome were found in the homozygous condition within heterokaryotypes. Hardy-Weinberg equilibrium theory predicts that one or more of the chromosomes not found in the B genome will occur in the homozygous form in 0.1337 of the plants within the population (Table 2). In our sample of 47 plants, no such individuals were found, representing a significant deviation from Hardy-Weinberg expectations $\left(\chi_{1}^{2}=6.15\right.$ including Yates's correction, $P<0.05)$. This suggests that the non-B-genome chromosomes are recessively lethal.

\section{Isoenzyme variation}

The results of the isoenzyme analysis are presented in Tables 3 and 4 . The four samples differed with respect to their levels of genetic diversity. The normal L. sessiliflora (PS) exhibited very little isoenzyme variation, with negligible observed heterozygosity. Among 139 electrophenotype determinations from this population, only one heterozygote was in evidence $\left(H_{\mathrm{o}}=0.007\right)$. The $L$. ramosa populations, $\mathrm{PR}$ and $\mathrm{CR}$, were more and comparably $\left(\chi_{1}^{2}=3.53\right.$, NS) diverse, exhibiting 19 and 24 heterozygotes amongst 181 and 178 electrophenotypes, respectively (mean $H_{\mathrm{o}}=0.120$ ). However, there was a deficiency of heterozygotes in these samples, mean $H_{\mathrm{e}}$ being 0.125 and 0.215 , respectively, with an overall mean of 0.170 . From these figures, $F=0.294$ and the outcrossing rate, $t=(1-F) /(1+F)=0.546$ over the two $L$. ramosa samples, the recurrent selfing rate $s=1-t=0.454$.

CS*, the Collie L. sessiliflora* population, was the most diverse, exhibiting 40 heterozygotes amongst 179 electrophenotypes $\left(H_{\mathrm{o}}=0.223\right)$, although only two of the six loci were polymorphic. There was a significant shortage of homozygotes at the $P G M$ locus in this population; 25 of the 30 PGM electrophenotypic determinations were of heterozygotes, giving an $F$-value of -0.7 . The $F$-value associated with the GPI-2 locus in the CS* sample was also negative.

Two plants of the CS* sample used for isoenzyme analysis were also karyotyped, and both were BB 
Table 2 A worksheet showing how the $\chi^{2}$ value associated with the zero occurrence of plants which were homozygous for one or more of the chromosomes not found in the B genome of Laxmannia was calculated. See Fig. 1 for definitions of the chromosome types. There are only two non-B alternatives to the fused 14 chromosome found in genome B, (1 and 4$)$ and (1+ + and 4$)$. There were 20 of these alternatives amongst the 47 plants ( 94 genomes). The expected frequency of non-B 1/4 chromosome homozygotes is therefore $(20 / 94)^{2}=0.0453$. Similarly, the expected frequency of non-B 2 chromosome homozygotes is $(1 / 94)^{2}=0.0001$ and the expected frequency of non-B 3 chromosome homozygotes is $(29 / 94)^{2}=0.0925$. The expected frequency of plants homozygous for one or more non-B chromosomes is therefore $1-(1-0.0435)(1-0.0001)(1-0.0925)=0.1337$

\begin{tabular}{|c|c|c|c|c|c|c|c|c|c|c|c|}
\hline Karyotypes & No. of plants & \multicolumn{10}{|c|}{ No. of chromosome types per karyotype } \\
\hline $\mathrm{AD}, \mathrm{BC}$ & 12 & 1 & 1 & & 1 & 2 & & 1 & 1 & & \\
\hline $\mathrm{BD}$ & 14 & 2 & & & & 2 & & 1 & 1 & & \\
\hline $\mathrm{AB}$ & 6 & 1 & 1 & & 1 & 2 & & 2 & & & \\
\hline BG & 1 & 2 & & & & 2 & & 1 & & 1 & \\
\hline Total & 47 & 74 & 18 & 2 & 20 & 93 & 1 & 65 & 27 & 1 & 1 \\
\hline $\begin{array}{l}\text { Expected frequency of } \\
\text { non-B chromosome homozygotes }\end{array}$ & & \multicolumn{4}{|c|}{0.0453} & \multicolumn{2}{|c|}{0.0001} & \multicolumn{4}{|c|}{0.0925} \\
\hline$\chi^{2}$ (with Yates's correction) & & \multicolumn{4}{|c|}{6.15} & & & & & & \\
\hline
\end{tabular}

homokaryotypes. Both of these homokaryotypes were heterozygous at the GPI-2 locus (1.4), one was homozygous at the $P G M$ locus (3.3) and the other was heterozygous (2.3).

Three of the alleles in CS* were present in one or both L. ramosa samples (PR and CR) but not in PS. The allozyme data were used to construct a UPGMA dendrogram (Fig. 2) based on a genetic distance matrix calculated according to the methods of Nei (1978). The cladogram indicates that CS* is most similar to CR, PR is next most similar to these, whereas PS is the most distinct, and basal to the other three.

\section{Discussion}

Laxmannia sessiliflora and L. ramosa are, generally, readily separable from each other on the basis of their morphology and genetic systems. Laxmannia sessiliflora has sessile inflorescences, one ovule per locule, and is open-pollinating, free of seed-aborting lethals and has little allozyme diversity, at least in the population sampled (PS). On the other hand, L. ramosa has pedunculated inflorescences, two ovules per locule, and is highly self-pollinated because its anthers are adpressed to the stigma at flower closure; in addition its populations are polymorphic for seed-aborting lethals, which are readily demonstrable by comparing seed-sets following experimental selfing and crossing. The species also exhibits much higher levels of genetic diversity at allozyme loci.

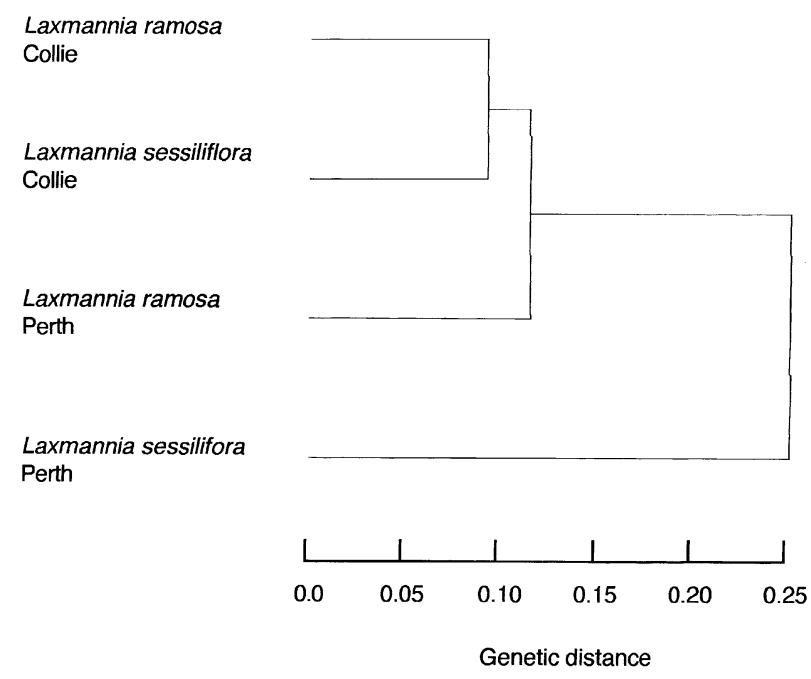

Fig. 2 UPGMA dendrogram of genetic distance matrix using the methods of Nei (1978).

(C) The Genetical Society of Great Britain, Heredity, 82, 364-372. 
It is reasonable to expect that lethal polymorphisms would resist the approach to homozygosity promoted by self-pollination at flower closure only for those loci linked to the lethals or components of lethal equivalents. The $F$-values at individual loci within the $L$. ramosa population samples, ranging from 1 to -0.17 (Table 3), support this contention. The average of the $F$-determinations for the two L. ramosa samples presented in Table 4 allows us to estimate that the level of inbreeding in that species is equivalent to a recurrent selfing rate less than $50 \%$. This figure is much less than the $\pm 75 \%$ estimated from fruit- and seed-setting patterns in the field, and is likely to be an underestimate because it would be confounded with the selection for heterozygosity engendered by the polymorphism for seed-aborting lethals. However, all significant departures from Hardy-Weinberg genotype frequency distributions in this species were associated with an excess of homozygotes, or a shortage of heterozygotes. This probably reflects the expected outcome of inbreeding associated with self-pollination at flower closure and suggests that the loci showing a shortage of heterozygotes were not closely linked to components of the recessive lethal equivalents. The effect of the lethal polymorphism is perhaps seen in the absence or reduced frequencies of certain homozygotes (see Table 3), suggesting that those loci were linked to lethal equivalent components, and in the much greater level of genetic diversity in terms of the percentage of polymorphic loci $(P)$ and the number of alleles at polymorphic loci $(A)$ compared with L. sessiliflora (PS) (Table 4).

The average of the $F$ determinations for Collie L. sessiliflora* $\left(\mathrm{CS}^{*}\right)$ presented in Table 4 is negative $(-0.47)$ and indicates that the population is totally outbreeding. However, self-pollination at flower closure is characteristic of the population, so that this estimate cannot be true and is, in all probability, confounded by a recessive lethal polymorphism. The existence of a lethal polymorphism in the CS* population is indicated by: (i) the fact that six of the seven haploid genomes identified in the population occurred only as heterozygotes; (ii) the significant shortage of plants homozygous for one or more of the chromosomes not occurring in the B genome; (iii) excessive allozyme heterozygosity and the absence of 2.2 homozygotes at the $P G M$ locus, which was statistically significant; and (iv) the absence of 1.1 and 3.3 homozygotes at the GPI-2 locus. The negative $F$-values at both polymorphic loci suggest that the lethal polymorphisms in this population are particularly intense.

The lethal polymorphisms maintaining high levels of genetic diversity in both $L$. ramosa and the CS* population impart a facade of outbreeding, if we measure their breeding systems in terms of $F$. However,

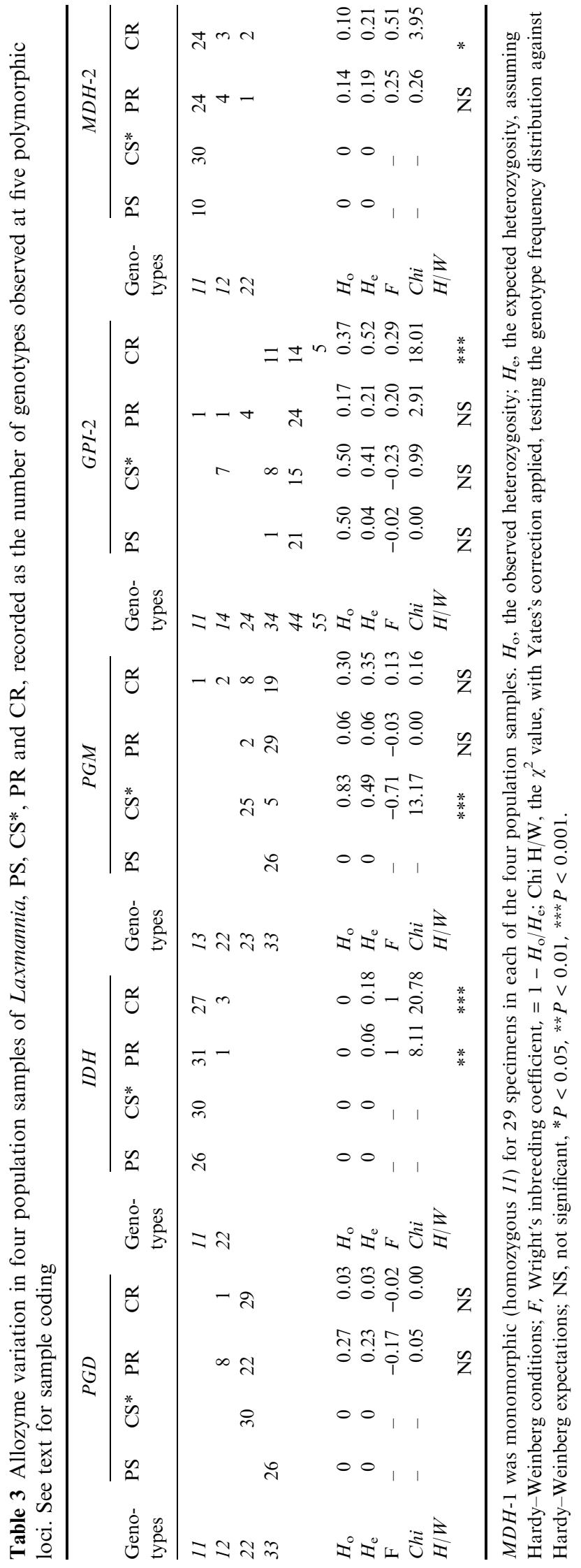


Table 4 Genetic diversity parameters for the four population samples, detailed in Table 3 , based on six loci

\begin{tabular}{llcccr}
\hline Sample & $A$ & $P$ & $H_{\mathrm{o}}$ & $H_{\mathrm{e}}$ & $F$ \\
\hline PS & 1.2 & 16.7 & 0.01 & 0.01 & -0.02 \\
CS* & 1.5 & 33.3 & 0.22 & 0.15 & -0.47 \\
PR & 2.0 & 83.3 & 0.11 & 0.13 & 0.25 \\
CR & 2.2 & 83.3 & 0.13 & 0.21 & 0.38 \\
\hline
\end{tabular}

$A$, the mean number of alleles over all loci; $P$, the percentage of loci that were polymorphic in the sample; $H_{\mathrm{o}}$, the observed frequency of heterozygotes averaged over all loci; $H_{\mathrm{e}}$, the mean expected heterozygosity, averaged over all loci; $F$, Wright's inbreeding coefficient, averaged over polymorphic loci.

both forms are mainly self-pollinating through adpression of the anthers to the stigma at flower closure, and are highly inbreeding. Where high levels of inbreeding and recessive lethal polymorphisms are associated in a plant population, the use of $F$ to measure the breeding system may be quite unreliable.

We also note that the increase in ovule number from one per locule in L. sessiliflora, which does not carry seed-aborting lethal polymorphisms, to two in L. ramosa and $L$. sessiliflora*, which do, represents an obvious adaptation that would compensate, at least in part, for the seed abortion that results from the lethal polymorphisms.

The Collie L. sessiliflora* $\left(\mathrm{CS}^{*}\right)$ population combines the taxonomically most significant morphological attributes of $L$. sessiliflora, namely sessile inflorescences, with two ovules per locule and a breeding system similar to that of L. ramosa. CS* is also more similar, allelically, to L. ramosa in both the Perth and Collie regions (PR and $\mathrm{CR}$ ), and is especially similar to the nearby CR. These data suggest that $\mathrm{CS}^{*}$ is either a population of hybrid origin or a population which has uniquely diverged from a phylogenetic link between the two species.

Although the origin of the CS* population is likely to remain contentious until more extensive population genetical, cytological and molecular phylogenetic analyses are undertaken, the situation in this population is of special interest. There is here an undeniable association of a lethal polymorphism and high levels of inbreeding. These conditions are those which promote the genomic coalescence modelled by James (1992). And, indeed, 'coalesced' genomes, which have three chromosomes rather than four, have been elevated to a high frequency in the population $(78.7 \%)$. Stochastic effects associated with dispersal from this source population may be expected to found monomorphic $2 n=6$ populations, but a detailed search of the population system remains to be undertaken. Nevertheless, genomic coalescence driven by natural selection operating to reduce the genetic load associated with polymorphisms for seed-aborting recessive lethal equivalents and high levels of inbreeding (James, 1992) may here account for the dysploid reduction of chromosome number within (and perhaps between) populations.

Genomic coalescence was first proposed to account for the linkage of chromosomes by interchange hybridity during the initial evolution of ring-of-six (O6) complex hybrids in Isotoma petraea (James et al., 1990) and the phenomenon was then proposed to be of general importance in cytoevolutionary processes (James, 1992). The impact of this proposal on evolutionary literature has been negligible, possibly because few workers can easily accept that lethal polymorphisms and inbreeding can be commonly associated in plant populations. The demonstration of the occurrence of genomic coalescence in terms of chromosome number reduction in association with lethal polymorphisms and inbreeding in the Collie L. sessiliflora* population is therefore important, and supports the contention that the phenomenon may well be pertinent to the dysploid speciation in evidence in many groups of Australian plants which utilize lethal polymorphisms and selfpollination (James, 1996).

Although dysploid chromosome number variation is characteristic of many Australian native plant groups, the direction of the chromosome number change has been contentious. Traditionally, patterns of chromosome numbers within plant groups have been interpreted on the basis of a low primitive chromosome number for the angiosperms ( $x=7$ or thereabouts) with higher numbers being derived following one or more ancient polyploid events (palaeopolyploidy) (Stebbins, 1950; Smith-White, 1959; Raven, 1975; Ehrendorfer, 1976). However, the alternative proposal that primitive chromosome numbers are high and diploid, and evolution is commonly through descending dysploidy (James, 1981), is receiving considerable support in studies which combine chromosome number patterns with the precision of modern cladistic analysis. Such studies include Stace et al. (1993) (Rutaceae); Stace \& James (1996) (Lobelioideae); Stace et al. (1997) (Epacridaceae). The common association of hermaphroditism, inbreeding and seed-aborting lethal polymorphisms in many components of the Australian flora (James, 1996|8@:Æn ), the population genetic consequences of the association as outlined by James (1992), and the demonstration of the phenomenon in this study, provide a logical explanation of why genomic coalescence and descending dysploidy should be a feature of angiosperm evolution.

\section{Acknowledgements}

We thank the third year undergraduate students of the Botany Department, The University of Western Aus- 
tralia, who participated in this study as a class exercise in 1996. We also thank an anonymous referee for his comments on an earlier version of the paper.

\section{References}

CARSON, H. L., HARDY, D. E., SPIETH, H. T. AND STONE, W. S. 1970. The evolutionary biology of the Hawaiian Drosophilidae. In: Hecht, M. K. and Steere, W. C. (eds) Essays in Evolution and Genetics in Honor of Theodosius Dobzhansky, pp. 437543. Appleton Century Crofts, New York.

DAHLGREN, R. M. T., CLIFFORD, H. T. AND YEO, P. F. 1985. The Families of Monocotyledons. Springer-Verlag, Berlin.

DOBZHANSKy, TH. 1951. Genetics and the Origin of Species, 3rd edn. Columbia University Press, New York.

EHRENDORFER, F. 1976. Evolutionary significance of chromosomal differentiation patterns in gymnosperms and primitive angiosperms. In: Beck, C. B. (ed.) Origin and Early Evolution of Angiosperms, pp. 220-240. Columbia University Press, New York.

GRANT, v. 1971. Plant Speciation. Columbia University Press, New York.

JAMES, S. H. 1965. Complex hybridity in Isotoma petraea. I. The occurrence of interchange heterozygosity, autogamy and a balanced lethal system. Heredity, 20, 341-353.

JAMES, S. H. 1981. Cytoevolutionary patterns, genetic systems and the phytogeography of Australia. In: Keast, A. (ed.) Ecological Biogeography of Australia, pp. 763-782. Dr. W. Junk BV, The Hague.

JAMES, S. H. 1992. Inbreeding, self-fertilization, lethal genes and genomic coalescence. Heredity, 68, 449-456.

JAMES, S. H. 1996. Seed abortion and the evolution of genetic systems in some Australian native plant groups. In: Hopper, S. D., Chappill, J. A., Harvey, M. S. and George, A. S. (eds) Gondwanan Heritage: Evolution and Conservation of the Western Australian Biota., pp. 90-99. Surrey Beatty \& Sons, Chipping Norton.

JAMES, S. H., SAMPSON, J. F. AND PLAYFORD, J. 1990. Complex hybridity in Isotoma petraea. VII. Assembly of the genetic system in the $\mathrm{O}_{6}$ Pigeon Rock population. Heredity, 64, 289-295.
JAMES, S. H., PLAYFORD, J. AND SAMPSON, J. F. 1991. Complex hybridity in Isotoma petraea. VIII. Variation for seed aborting lethal genes in the O6 Pigeon Rock population. Heredity, 66, 173-180.

KeIGHeRY, G. K. 1987. Laxmannia. In: George, A. S. (ed.) Flora of Australia, vol. 45, pp. 254-264. Australian Government Publishing Service, Canberra.

NEI, M. 1978. Estimation of average heterozygosity and genetic distance from a small number of individuals. Genetics, 89 , $583-590$

RAVEN, P. H. 1975. The bases of angiosperm phylogeny: cytology. Ann. Mo. Bot. Gard., 62, 724-764.

SAMPSON, J. F., COllins, B. G. AND COATES, D. J. 1994. Mixed mating in Banksia brownii Baxter ex R. Br. (Proteaceae). Aust. J. Bot., 42, 103-111.

SMITH-white, S. 1959. Cytological evolution in the Australian flora. Cold Spring Harb. Symp. Quant. Biol., 24, 273289.

STACE, H. M. AND JAMES, S. H. 1996. Another perspective on cytoevolution in Lobelioideae (Campanulaceae). Am. J. Bot., 83, 1356-1364.

STACE, H. M., ARMSTrong, J. A. AND JAMES, S. H. 1993. Cytoevolutionary patterns in Rutaceae. Pl. Syst. Evol., 187, 1-28.

STACE, H. M., CHAPMAN, A. R., LEMSON, K. L. AND POWELL, J. M. 1997. Cytoevolution, phylogeny and taxonomy in Epacridaceae. Ann. Bot., 79, 283-290.

STEBBINS, G. L. 1950. Variation and Evolution in Plants. Columbia University Press, New York.

STEWART, D. A. AND BARLOW, B. A. 1976. Genomic differentiation and polyploidy in Sowerbaea (Liliaceae). Aust. J. Bot., 24, 349-367.

WAYCOTT, M., JAMES, S. H. AND WALKER, D. I. 1997. Genetic variation within and between populations of Posidonia australis, a hydrophilous, clonal seagrass. Heredity, 79, 408417.

WENDEL, J. F. AND WEEDEN, N. F. 1989. Visualisation and interpretation of plant isozymes. In: Soltis, D. E. and Soltis, P. S. (eds) Isozymes in Plant Biology, pp. 5-45. Dioscorides Press, Portland, OR.

WHITE, M. J. D. 1978. Modes of Speciation. W. H. Freeman, San Francisco. 